SSC08-IV-9

\title{
Geostationary Small Satellite for Operationally Responsive Space (ORS) \\ Communications Missions
}

\author{
Frank Taylor \\ Bryce Carpenter \\ Hannes Hacker \\ John Hibbs \\ Zach Thicksten \\ SpaceDev Inc \\ 13855 Stowe Dr, Poway, CA 92064; 858-375-2000 \\ frank.taylor@spacedev.com \\ Jason Hinkle \\ SpaceDev Inc \\ 1722 Boxelder St Suite \#102, Louisville, CO 80027; 720-407-3184 \\ jason.hinkle@spacedev.com
}

\begin{abstract}
Existing military communication systems use large, very expensive, heavily tasked "national asset" communications satellites located in geostationary orbits, often supplemented by leased capabilities on commercial satellites. As data and voice communication needs have increased with the adoption of network-centric warfare operations, these assets may becoming increasingly oversubscribed and unavailable when needed by tactical warfighters. The Air Force has established an office of Operational Responsive Space (ORS) to address these and other challenges.

The Geo Small Sat (GSS) concept is less complex than a LEO constellation system, employing only a single small $\mathrm{UHF} / \mathrm{L}$ Band communications satellite launched by a small responsive vehicle and self-boosted to a geostationary orbit over a region of interest. The small, highly capable satellite will be reconfigurable to support all UHF and L-band communication networks. Making this novel solution a reality will require the use of several key mission technologies:
\end{abstract}

- Compatibility with existing small responsive launch vehicles.

- A propulsion system capable of LEO-to-GEO transfer.

- A small satellite bus capable of supporting a communications payload adaptable for existing ground systems.

- A deployable antenna (18 meters in diameter), that can be packaged within the available launch vehicle’s volume. 


\section{INTRODUCTION}

Existing military communication (SATCOM) systems use large, very expensive, heavily tasked "national asset" communications satellites located in geostationary orbits, often supplemented by leased capabilities on commercial satellites. As data and voice communication needs have increased with the adoption of network-centric warfare operations, these assets are becoming increasingly oversubscribed and unavailable when needed by tactical warfighters. In addition, they do not always provide adequate security and coverage in the geographic areas where they are needed. The Air Force has established an office of Operational Responsive Space (ORS) to address these and other challenges.

Since the outset of the ORS initiative, warfighters have identified secured UHF communications for mobile and forward-deployed users as one of the highest priorities for mission success ${ }^{1}$.

All previous program efforts have focused on low-earth orbit (LEO) or highly-elliptical orbit (HEO) operations, which have limited utility due to short periods of overhead visibility, especially for LEO satellites. To overcome this limitation, most LEO operating concepts call for constellations of 4-6 satellites, increasing cost and operational complexity ${ }^{2}$.

The Geo Small Sat (GSS) concept is less complex than a LEO constellation system, employing only a single small UHF communications satellite with a large deployable antenna, located in a geostationary orbit over a region of interest. The proposed small, highly capable satellite will provide 24/7 communication coverage, will be adaptable to be able to overcome unintentional or hostile interference, and will be reconfigurable to support all UHF and L-band communication networks. Making this novel solution a reality will require the use of several key mission technologies:

- Compatibility with existing responsive launch vehicles capable of delivering the satellite into LEO .

- A GEO-transfer propulsion system capable of placing the satellite into the desired geostationary orbit from LEO.

- A small satellite capable of operating in a geosynchronous orbit and maintaining a communications payload weighing less than $120 \mathrm{~kg}$

- A deployable antenna (18 meters in diameter), that can be packaged within the available launch volume and weighing less than $132 \mathrm{~kg}$
The Geo Small Sat (GSS) incorporates all of these elements to provide warfighters with a communications capability that will far exceed that previously envisioned for LEO systems, while remaining compatible with the ORS goals of low-cost and responsiveness. This concept has a very high potential payoff, with reasonably low levels of risk due to previous demonstrations of the critical technologies.

\section{SYSTEM REQUIREMENTS}

There are two primary system requirements for GSS: One is to be compatible with an existing small responsive launch vehicle which is currently or soon to be supportive of DOD satellite deployment; the other is for the satellite communication payload to be compatible with current or soon to be deployed military tactical ground communication systems.

\section{LAUNCH VEHICLE}

The first primary system requirement indicates the evaluation of all small responsive launch vehicles. The list of launch vehicles ranges from SpaceX's Falcon to Orbital's Minotaur, Taurus and Pegasus. The Minotaur launch vehicles are considered by AFRL as a responsive capability at a cost-effective price ${ }^{3}$. Table 1 lists the published data for each of the candidate vehicles.

Table 1: US DOD Small Responsive Launch Vehicles

\begin{tabular}{|l|l|l|l|}
\hline \multicolumn{1}{|c|}{ Name } & \multicolumn{1}{c|}{ Orbit } & Inclination & Max Mass (Kg) \\
\hline Pegasus* & $400 \times 400$ & 0.0 & 390 \\
\hline Taurus 2110** & $500 \times 500$ & 4.0 & 900 \\
\hline Taurus 3100** & $600 \times 600$ & 4.0 & 1,075 \\
\hline Taurus 2210** & $800 \times 800$ & 4.0 & 675 \\
\hline Taurus 3210** & $700 \times 700$ & 4.0 & 850 \\
\hline Minotaur I*** & $185 \times 1000$ & 28.5 & 500 \\
\hline Minotaur IV*** & $185 \times 1000$ & 28.5 & 1,500 \\
\hline Falcon I **** & $400 \times 400$ & 9.0 & 625 \\
\hline Falcon I **** & $800 \times 800$ & 9.0 & 550 \\
\hline
\end{tabular}

The Minotaur IV is capable of launching the GSS from the Reagan Test Site (RTS), delivering $1,750 \mathrm{~kg}$ to a 185 x $1,000 \mathrm{~km}$ orbit with a $9^{\circ}$ inclination. ${ }^{8}$ Minotaur IV was chosen because it has one of the best mass/dollar capabilities of current launch vehicles at $\$ 5,100 / \mathrm{lb} .^{3}$ Figure 1 shows the GSS incorporated into the Minotaur IV launch vehicle. 


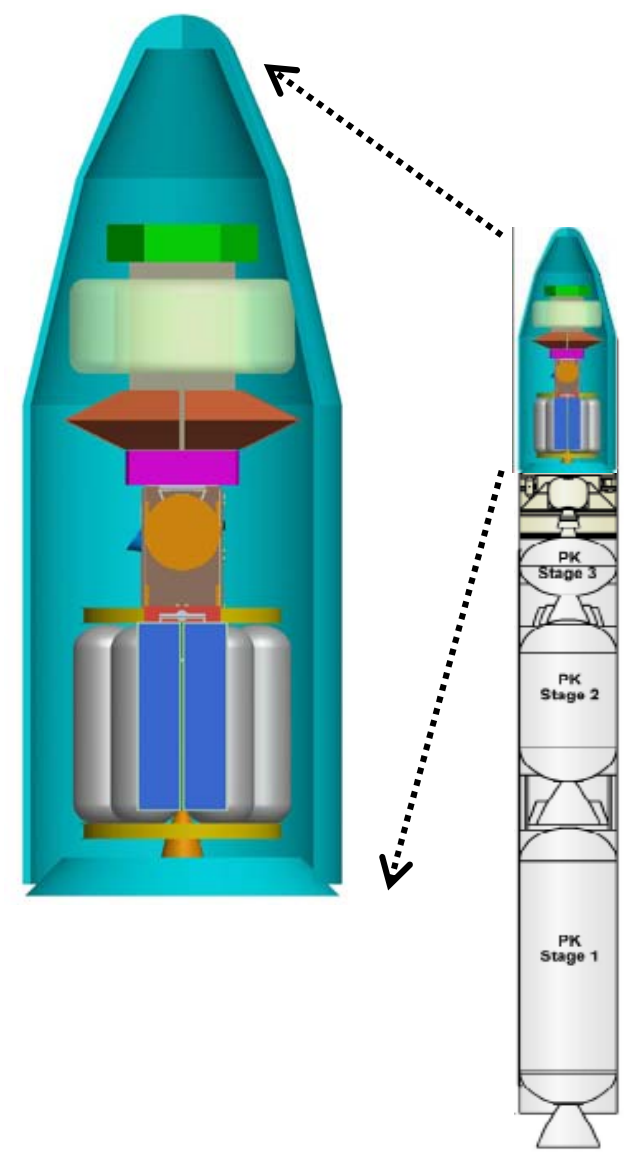

Figure 1: Cross-section of Minotaur IV w/ GSS

\section{INTEGRATED PROPULSIONS SYSTEM (IPS)}

The Integrated Propulsion system (IPS) needed to transfer the GSS from LEO to GEO will be either a Nitrous Oxide/Ethane or a Hydrazine/Nitrogen Tetroxide bipropellant system. Each of these systems will provide a specific impulse $\left(\mathrm{I}_{\mathrm{sp}}\right)$ of 300 seconds or greater. The bipropellant hydrazine system is based on the existing flight-qualified AmPac ISP LEROS $1 \mathrm{~B}$. $^{9}$ The $\mathrm{I}_{\mathrm{sp}}$ for the LEROS 1B is 318 seconds, as shown in Figure 2.

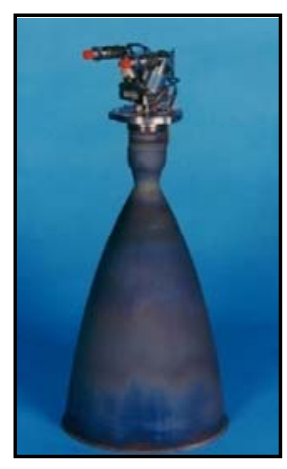

\begin{tabular}{|l|c|}
\hline MODEL & LEROS 1B \\
\hline Fuel (NTO oxid.) & Hydrazine \\
\hline Thrust & $645 \mathrm{~N}$ \\
\hline Specific Impulse & $318 \mathrm{~s}$ \\
\hline Area Ratio & $150: 1$ \\
\hline Inlet Pressure Range & $14.3-19.6 \mathrm{bar}$ \\
\hline Max. Impulse & $12,900,000 \mathrm{~N}-\mathrm{s}$ \\
\hline Minimum Impulse Bit & - \\
\hline Weight & $4.1 \mathrm{~kg}$ \\
\hline Engine Length & $647 \mathrm{~mm}$ \\
\hline Nozzle Exit Diameter & $289 \mathrm{~mm}$ \\
\hline Status & Flight Qualified \\
\hline
\end{tabular}

Figure 2: AmPac’s LEROS 1B Bipropellant Hydrazine Data ${ }^{9}$

The reason for using a lower $\mathbf{I}_{\mathbf{s p}}$ (300 vs. 318) for the sizing of the integrated propulsion system (IPS) is that it facilitates the use of an alternate non-toxic propellant system. One such system is a Nitrous Oxide/Ethane bipropellant system. The advantage of the Nitrous Oxide/Ethane is that both propellants are self-pressurized and non-cryogenic for long-term storage in space. ${ }^{10}$ This system is not flight-proven, but has great potential to remove the hazardous handling and environmental effects of a hydrazine system.

The IPS will perform a burn at the parking orbit's perigee to raise the apogee to geosynchronous altitude, where it will perform a circularization burn. Assuming a $185 \mathrm{x}$ $1000 \mathrm{~km}$ parking orbit and using a Hohmann transfer, a total delta- $\mathrm{V}$ of $4,160 \mathrm{~m} / \mathrm{s}$ is needed to achieve geostationary orbit (calculated using AGI's STK Astrogator software). Once on station, the propulsion system's primary and RCS thrusters will be used for future burns to perform momentum wheel desaturation, station keeping, and end-of-life disposal. These on-station maneuvers will require a total delta- $\mathrm{V}$ of $184.3 \mathrm{~m} / \mathrm{s}$ for a 
three year mission. This is based on $53.5 \mathrm{~m} / \mathrm{s}$ for North/South plus $1.8 \mathrm{~m} / \mathrm{s}$ for East/West station-keeping per year at GEO. ${ }^{11}$ Spacecraft disposal, conducted in accordance with United States Space Command Policy Directive $10-39{ }^{12}$ will require an additional $18.4 \mathrm{~m} / \mathrm{s}$. The total delta-V needed for transfer to GEO and 3 year mission operations is $4,345 \mathrm{~m} / \mathrm{s}$.

To support this total impulse, the IPS can use either of the previously mentioned propellant systems, and will weigh $<1,500$ kilograms based on a mass fraction of .90 and an $\mathrm{I}_{\mathrm{sp}}$ of 300 . The remaining mass allowable for the satellite and payload is $250 \mathrm{~kg}$, based on the Minotaur IV capability of delivering $1,750 \mathrm{~kg}$ to the parking orbit from RTS. This mass allocation analysis highlights the critical primary requirement of the GSS system to be massefficient.

The IPS will meet the mass requirements by receiving its attitude determination, navigational data, and communications from the satellite bus. In turn, the propulsion system's support structure provides electrical power to both itself and the satellite bus on orbit. This configuration reduces the GNC, comm., and power hardware boxes required for the system, thereby saving weight and cost. Unlike typical booster propulsion systems, it will remain with the bus on orbit.

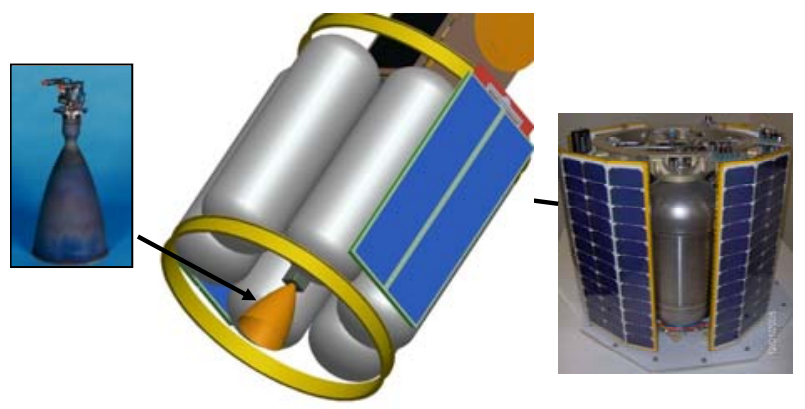

Figure 3: Integrated Propulsion System (IPS) Incorporates Solar Arrays

\section{SOFTWARE-DEFINED RADIO (SDR) PAYLOAD}

The Software Defined Radio Payload (SDR) provides the theater commander with secured high bandwidth ondemand communications. The payload will support over 400 simultaneous users in UHF at $256 \mathrm{Kbps}$ across a widely dispersed theater of up to $1,800 \mathrm{~km}$ in diameter (Figure 4). The UHF MUOS-type man-portable handset was defined as the baseline ground communication unit for the purpose of this study; however, many other existing military ground systems are compatible with the payload, including but not limited to Blue Force tracking and UFO.

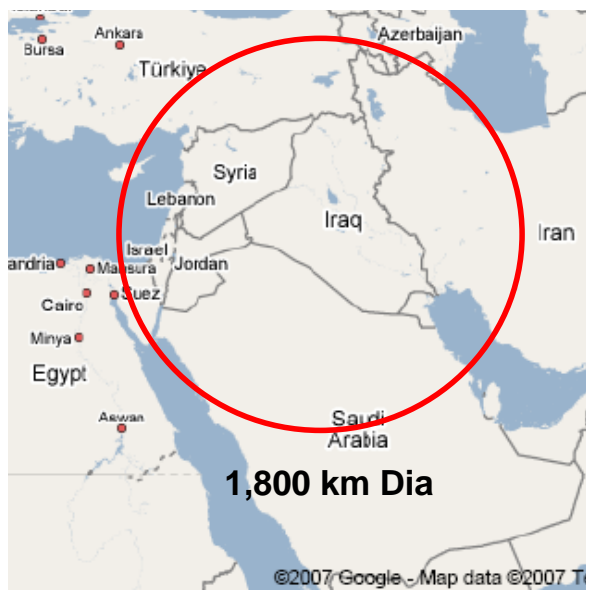

Figure 4: Coverage Area of a 1,800 $\mathrm{km}$ Diameter at UHF Frequencies

Developed under a study contract with NRL, the SDR Payload is based on a reconfigurable, multi-mode, multimission radio which provides autonomous, distributed voice and data communications among widely and dissimilar tactical assets. Figure 5 shows the SDR developed by Assurance Technology Corp (ATC) of Carlisle $\mathrm{MA}^{13}$ with a total mass of $9.1 \mathrm{~kg}$.

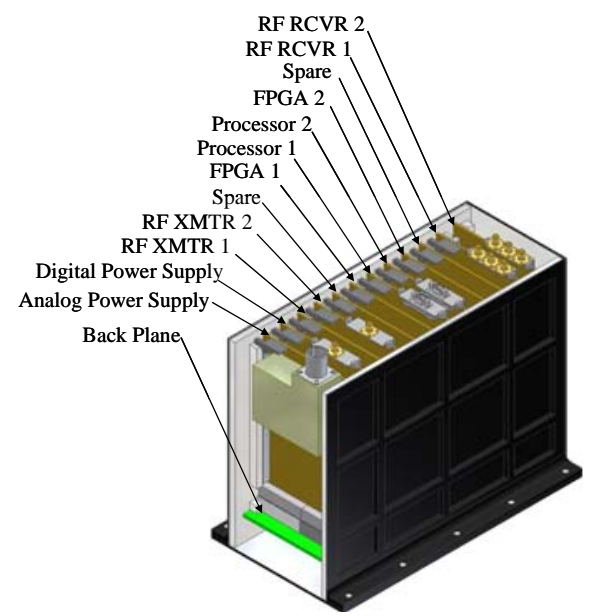

Dimensions: $11.7 \mathrm{~cm} \times 21.0 \mathrm{~cm} \times 29.0 \mathrm{~cm}$ Weight: $9.1 \mathrm{~kg}$

Figure 5: Software Defined Radio by Assurance Technology Corp (ATC) of Carlisle MA ${ }^{13}$ 
Due to changing tactical situations, the payload can be reconfigured in real-time to meet the desired operational mission requirements. The payload uplink and downlink frequencies and bandwidths are tunable across UHF (244 $\mathrm{MHz}$ ) to L-band (2.1GHz) to support "Comms on the Move”.

The transmit band is 360 to $380 \mathrm{MHz}$ for MUOS handsets. The GSS Deployable antenna is sized at 18 meters in diameter to enable high-speed links with low gain ground antennas for the MUOS tactical system. The 18-m diameter GSS antenna at 256 Kbps combined with the MUOS compatible handset at either 5W EIRP with a $6 \mathrm{dBi}$ gain antenna or $10 \mathrm{~W}$ EIRP with a $3 \mathrm{dBi}$ gain antenna, achieves a link margin > $5.7 \mathrm{~dB}$ (Table 2). ${ }^{14}$

Table 2: MUOS Link Path Analysis ${ }^{14}$

\begin{tabular}{|l|l|l|l|}
\hline Uplink Transmitter Power Output: & 5.0 & 10.0 & watts \\
\hline \multicolumn{1}{|c|}{ In dBW: } & 7.0 & 10.0 & $\mathrm{dBW}$ \\
\hline Misc. Line Losses: & -2.0 & -2.0 & $\mathrm{~dB}$ \\
\hline Antenna Gain: & 6.0 & 3.0 & $\mathrm{dBiC}$ \\
\hline Ground Station EIRP: & 11.0 & 11.0 & $\mathrm{dBW}$ \\
\hline Uplink Path: & & & \\
\hline $\begin{array}{l}\text { Path Loss @ 360 MHz, 40,800 km } \\
\text { range: }\end{array}$ & -175.8 & -175.8 & $\mathrm{~dB}$ \\
\hline Misc path Losses: & -3.0 & -3.0 & $\mathrm{~dB}$ \\
\hline $\begin{array}{l}\text { Isotropic Signal Level at Ground } \\
\text { Station: }\end{array}$ & -167.8 & -167.8 & $\mathrm{dBW}$ \\
\hline Spacecraft: & & & \\
\hline Spacecraft Antenna Gain: & 30.0 & 30.0 & $\mathrm{dBiC}$ \\
\hline $\begin{array}{l}\text { Spacecraft Transmission Line } \\
\text { Losses: }\end{array}$ & -1.0 & -1.0 & $\mathrm{~dB}$ \\
\hline Spacecraft LNA Noise Temperature: & 90 & 90 & $\mathrm{~K}$ \\
\hline Spacecraft Transmission Line Temp.: & 270 & 270 & $\mathrm{~K}$ \\
\hline Spacecraft Sky Temperature: & 290 & 290 & $\mathrm{~K}$ \\
\hline S/C Transmission Line Coefficient: & 0.7943 & 0.7943 & \\
\hline $\begin{array}{l}\text { Spacecraft Effective Noise } \\
\text { Temperature: }\end{array}$ & 376 & 376 & $\mathrm{~K}$ \\
\hline Spacecraft Figure of Merit (G/T): & 3.2 & 3.2 & $\mathrm{~dB} / \mathrm{K}$ \\
\hline $\begin{array}{l}\text { S/C Signal-to-Noise Power Density } \\
\text { (S/No): }\end{array}$ & 64.3 & 64.3 & $\mathrm{dBHz}$ \\
\hline System Desired Data Rate: & 256000 & 256000 & $\mathrm{bps}$ \\
\hline & 54.1 & 54.1 & $\mathrm{dBHz}$ \\
\hline Telemetry System Eb/No: & 10.3 & 10.3 & $\mathrm{~dB}$ \\
\hline $\begin{array}{l}\text { Telemetry System Required Bit Error } \\
\text { Rate: }\end{array}$ & $1.00 \mathrm{E}-$ & $1.00 \mathrm{E}-$ & \\
\hline $\begin{array}{l}\text { Telemetry System Required Eb/No } \\
\text { (BPSK/FEC): }\end{array}$ & 4.6 & 4.6 & $\mathrm{~dB}$ \\
\hline System Link Margin: & 5.7 & 5.7 & $\mathrm{~dB}$ \\
\hline
\end{tabular}

The compatibility of the low gain ground antennas enables mobile tactical units to receive and transmit highspeed data while on the move. This is especially important relative to today's convoy communication requirements for real-time data to the warfighters.

In addition to supporting the military communication frequencies (UHF and S-band) for tactical units, the GSS system is adaptable to commercial wireless frequencies (cellular service from $700 \mathrm{MHz}$ to $2.1 \mathrm{GHz}$ ).

\section{DEPLOYABLE ANTENNA}

The 18-m antenna system uses a deployable reflector structural architecture with heritage going back to the 1980s (Figure 6). This design has been updated with the latest deployable structures technology through an ongoing development effort over the last four years. As a result of this work, the hoop and column deployable dish architecture meets the system's mass goal $(132 \mathrm{~kg})$ and enables it to fit in a Minotaur IV launch vehicle fairing.

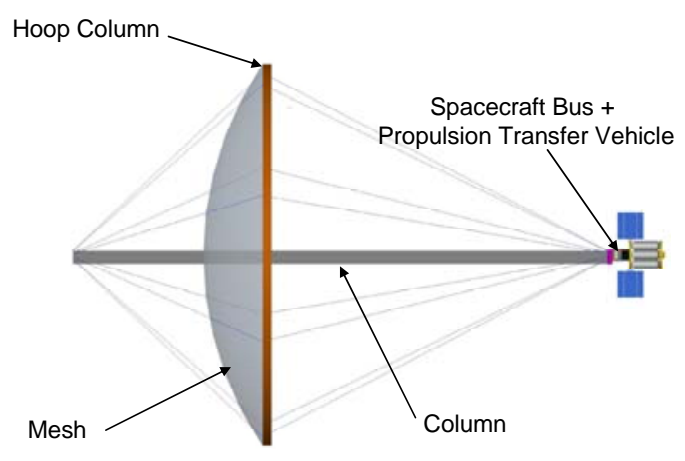

Figure 6: 18-m Diameter Antenna, Deployed

The hoop structural element is formed by three deployable booms, attached end-to-end and forming a triangle shape when packaged. As shown in Figure 7, the three booms are deployed simultaneously, forming a hoop that grows in diameter as the booms deploy. The boom deployment unfurls a mesh reflector. Once the hoop is fully formed, a fourth boom is deployed normal to the plane of the hoop, forming the "column". This column is attached at both ends by deploying lanyards that keep it located in the hoop's center. One end of the column is attached to the spacecraft bus, at the reflector's focal point. At the other end, the boom attaches several reflector-shaping lanyards as well as the hoop attachment lanyards. 

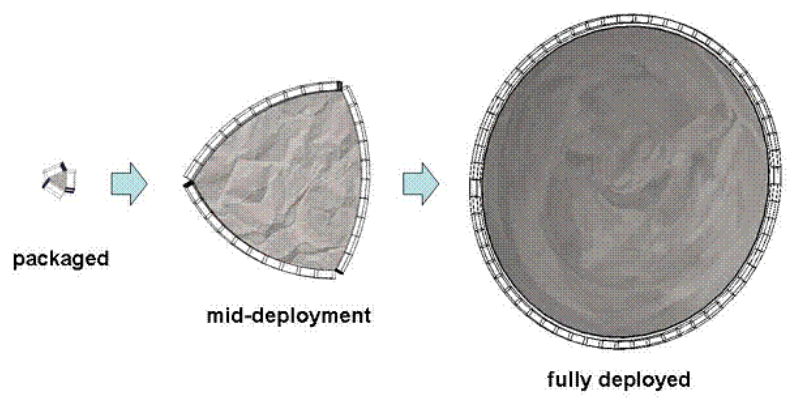

Figure 7: 18-m Antenna Deployment

The resulting deployable structure acts as both the structure and focus boom. A small prototype of this concept was constructed and successfully deployed in the 1980's by NASA Langley. ${ }^{15}$ At the time, the existing boom technologies did not allow mesh attachment at the required number of locations on the hoops, making the system overly complex.

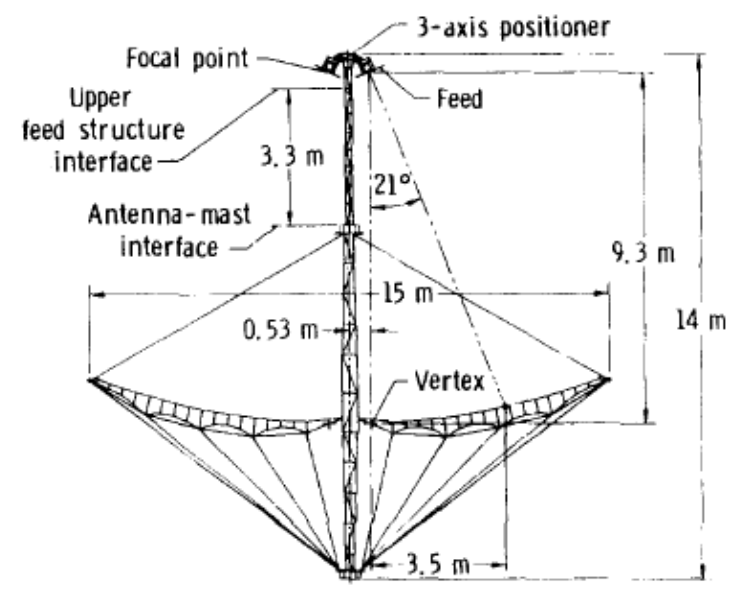

Figure 8: 1980 's NASA Langley Study ${ }^{15}$

Current Jackscrew boom technology overcomes this limitation. In contrast to prior deployable booms, the batten frames in a Jackscrew boom are translated along the boom's axis. In addition, these batten frames are exposed and available for payload integration throughout the deployment process. (Prior coilable and articulated boom systems involve rotational batten frame kinematics and require deployment canisters which hamper payload integration.)
As a result, the Jackscrew boom technology has enabled a robust, large-diameter deployable reflector that can be packaged into a compact volume for launch. A detailed mass breakdown of the antenna is listed Table 3. The photos in Figure 9 show the Jackscrew boom technology during a ground test.

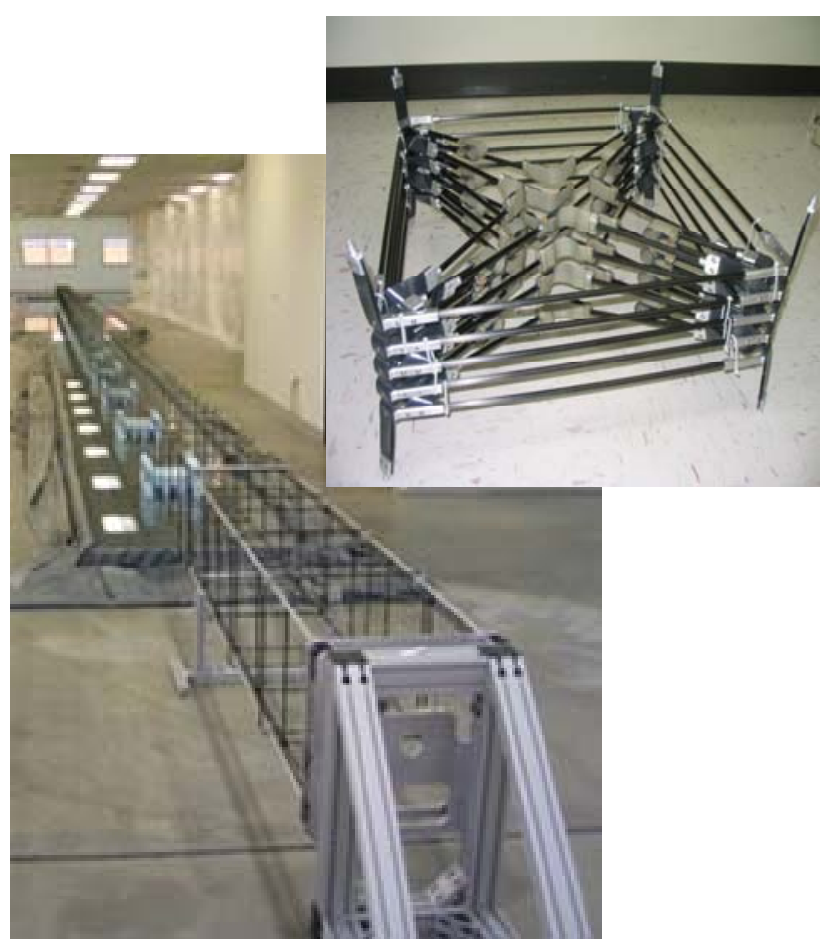

Figure 9: Jackscrew Boom Technology 
Table 3: 18-m Diameter Antenna Mass Breakdown

\begin{tabular}{|l|l|l|l|l|l|}
\hline \multicolumn{1}{|c|}{ Item } & Qty & $\begin{array}{c}\text { Comp } \\
\text { Wt }\end{array}$ & \multicolumn{1}{|c|}{$\begin{array}{c}\text { Item } \\
\text { Total }\end{array}$} & Cont. & $\begin{array}{c}\text { Total } \\
\text { (Kg) }\end{array}$ \\
\hline Ant Assm & & & & & \\
\hline Lanyards & 1018 & 0.017 & 17.1 & $20 \%$ & 20.5 \\
\hline Handling Box & 1 & 6.8 & 6.8 & $20 \%$ & 8.2 \\
\hline Mesh Handling & 1 & 6.8 & 6.9 & $20 \%$ & 8.2 \\
\hline Mesh & 1 & 3.6 & 3.6 & $20 \%$ & 4.3 \\
\hline \multicolumn{1}{|c|}{ SUBTOTAL } & & & $\mathbf{3 4 . 3}$ & & $\mathbf{4 1 . 2}$ \\
\hline ANT Structure & & & & & \\
\hline $\begin{array}{l}\text { Launch } \\
\text { Restraints }\end{array}$ & 4 & 2.3 & 91. & $20 \%$ & 10.9 \\
\hline $\begin{array}{l}\text { Column Boom } \\
\text { Deployer }\end{array}$ & 1 & 4.5 & 4.5 & 0 & 4.5 \\
\hline Column Boom & 1 & 9.0 & 9.0 & 0 & 9.0 \\
\hline $\begin{array}{l}\text { Hoop } \\
\text { Deployment }\end{array}$ & 3 & 4.5 & 13.6 & $20 \%$ & 16.4 \\
\hline Hoop Boom Seg & 3 & 9.0 & 27.1 & 0 & 27.1 \\
\hline Hoop Boom Dep & 3 & 4.5 & 13.6 & 0 & 13.6 \\
\hline Hoop IF to SC & 1 & 1.4 & 1.4 & $20 \%$ & 1.6 \\
\hline Harnessing & 1 & 2.3 & 2.3 & $20 \%$ & 2.7 \\
\hline Misc & 1 & 4.5 & 4.5 & 0 & 4.5 \\
\hline $\begin{array}{c}\text { SouBTOTAL } \\
\text { TOTAL }\end{array}$ & & & $\mathbf{8 5 . 3}$ & & $\mathbf{9 0 . 6}$ \\
\hline & & & $\mathbf{1 1 9 . 6}$ & & $\mathbf{1 3 1 . 8}$ \\
\hline
\end{tabular}

A useful reference for comparison may be found in NASA's CR-2004-213053 report ${ }^{16}$, which graphs the mass vs. diameter of existing deployable antennas. As shown in Figure 10, the GSS deployable antenna (130 kg at $18-\mathrm{m}$ in diameter) is close to the best fit line for mesh deployable antennas. The best fit line (does not include the $225 \mathrm{~kg} / 10-\mathrm{m}$ data point due to its large variance from the rest of the data) and the GSS antenna was added to the NASA chart in Figure 10.

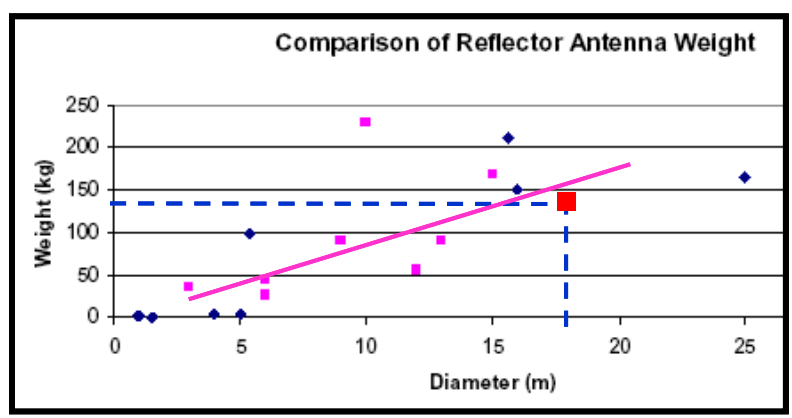

Figure 10: 18M Antenna Deployment ${ }^{16}$

\section{SATELLITE BUS}

The composite constructed bus houses a standard suite of satellite components. The bus integrates both payload and propulsion functions by sharing sensors, computers, and power between subsystems and common structural elements. The total mass budget allocation (Table 4) for the payload and bus is $<250 \mathrm{~kg}$. Note that the $18-\mathrm{m}$ antenna mass has an additional contingency factor of $10 \%$ added on top of the contingency already applied in the detailed antenna mass breakdown.

Table 4: GSS Bus and Payload Weight Allocation

\begin{tabular}{|l|l|l|l|}
\hline \multicolumn{1}{|c|}{ Item } & \multicolumn{1}{|c|}{$\begin{array}{c}\text { Allocation } \\
\text { (kg) }\end{array}$} & Contingency & $\begin{array}{c}\text { Max } \\
\text { Wt } \\
\text { (kg) }\end{array}$ \\
\hline $\begin{array}{l}\text { 18m Dia Antenna } \\
\text { System }\end{array}$ & 132 & $10 \%$ & 145.2 \\
\hline $\begin{array}{l}\text { Solar Arrays (400W) } \\
\text { 3 sq m }\end{array}$ & 9.0 & $10 \%$ & 9.9 \\
\hline HPA x 2 (200W) & 14.5 & $10 \%$ & 16.0 \\
\hline Soft Radio (75W) & 9.1 & $10 \%$ & 10.0 \\
\hline RF Horn & 2.0 & $10 \%$ & 2.2 \\
\hline Bus Hardware & 4.2 & $10 \%$ & 4.6 \\
\hline Avionics Deck (120W) & 21.5 & $10 \%$ & 23.7 \\
\hline Transition Adapter & 14.3 & $10 \%$ & 15.7 \\
\hline Battery (1,040 Whrs) & 9.3 & $10 \%$ & 10.2 \\
\hline Harness + Thermal & 10 & $20 \%$ & 12.0 \\
\hline GSS Satellite Total & $\mathbf{2 2 5 . 9}$ & $\mathbf{1 2 \%}$ & $\mathbf{2 4 9 . 5}$ \\
\hline
\end{tabular}

The payload-to-bus interface is geometrically sandwiched between the propulsion system and deployable antenna. The propulsion system uses the IMU, flight computer, sensors and communication components from the bus to navigate the GSS from LEO to GEO. The major components supporting the GSS mission are: three A-size reaction wheels, flight computer, S-band satellite communication system, star tracker and IMU, as well as payload avionics and batteries to power both the bus and payload throughout the maximum solar eclipse of 70 minutes. The Li-ion batteries have been sized for 1040 watt-hours to supply the continuous 400 watts required 
for the bus's 120-W load and payload's 275-W load, during eclipse. The allocated mass for the solar array is based on $3 \mathrm{~kg} / \mathrm{sq}$ meter.

The interface between the IPS and bus includes power, since the deployable solar arrays (3 sq meter area) are mounted to the IPS to allow placement of the feed antenna and radiator on the bus housing, and minimize solar blockage due to the IPS. The structural interface is through the mounting location atop the IPS, which will remain attached for the entire mission.

The structural interface between the bus and payload is the drive mechanism of the deployable antenna attachment at the edges of the bus's top deck. There are only electrical (motor drives) and sensor/data interfaces between the bus and antenna payload. The payload avionics (radio and amplifier) are mounted internally to the bus. There is an added interface between the bus and $\mathrm{RF}$ feed for the antenna. The RF feed is a circular antenna hinged to the side of the bus to radiate the reflector.

\section{GEO SMALL SAT OVERALL CONCEPT SUMMARY}

The proposed system uses an 18-meter diameter deployable mesh dish reflector. While deployable mesh reflectors have been used for many years on large communication satellites, the GSS will use a new type of deployable reflector that can be packaged into a much smaller volume than existing 18-meter systems, by using the hoop and column technology. Figure 11 shows the stowed configuration of the GSS. Figure 12 andFigure 13 show the deployed configuration of GSS with the reflector and the solar array deployed. The combination of the 18-m diameter antenna and the software defined radio enables high speed (256 Kbps) communication with tactical military MUOS equipment.

In addition to the antenna, the other enabling technology is the adaptation of existing propulsion systems to generate adequate delta- $\mathrm{V}$ to place a useful payload in GEO while using a small responsive launch vehicle like the Minotaur IV. The volume and weight constraints of the launch vehicle have been met, thereby enabling the rapid deployment of 24/7 GEO communication with a single satellite, as compared to a network of multiple LEO satellites.

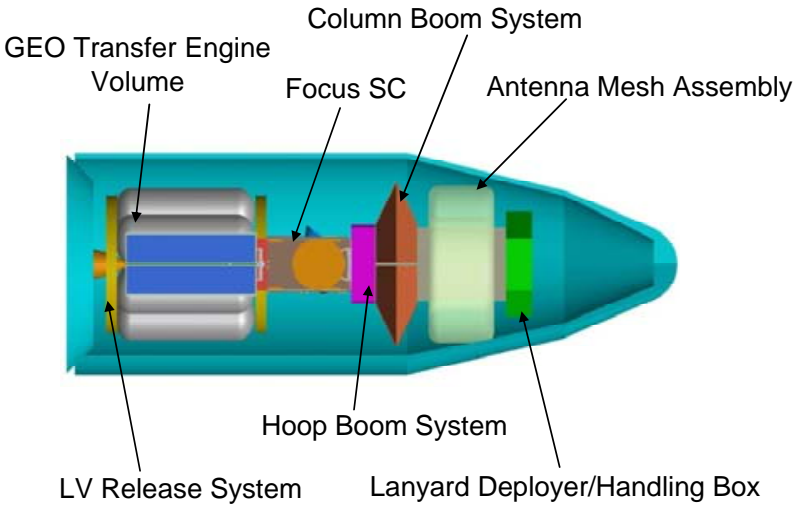

Figure 11: GSS is Compatible with the Minotaur IV Fairing

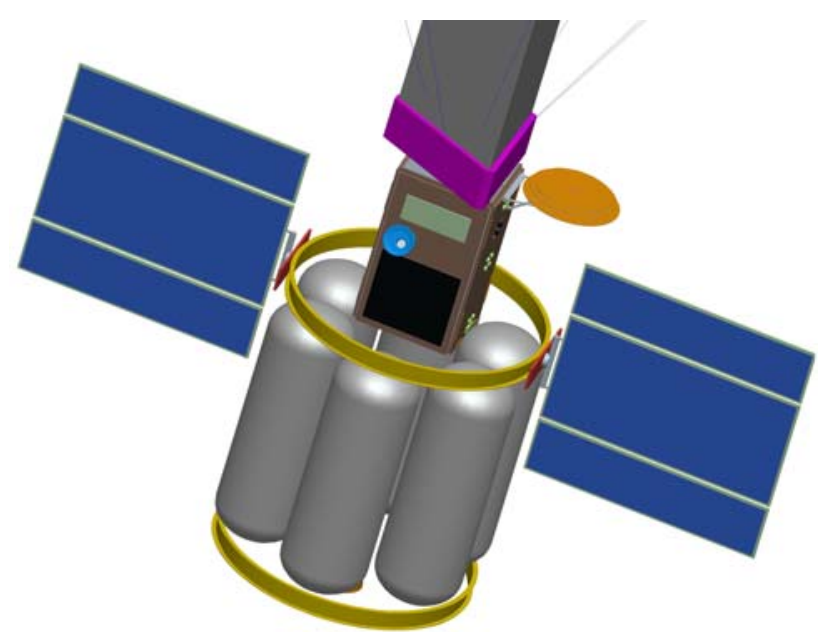

Figure 12: GSS Bus and Propulsion System in the Deployed Configuration 


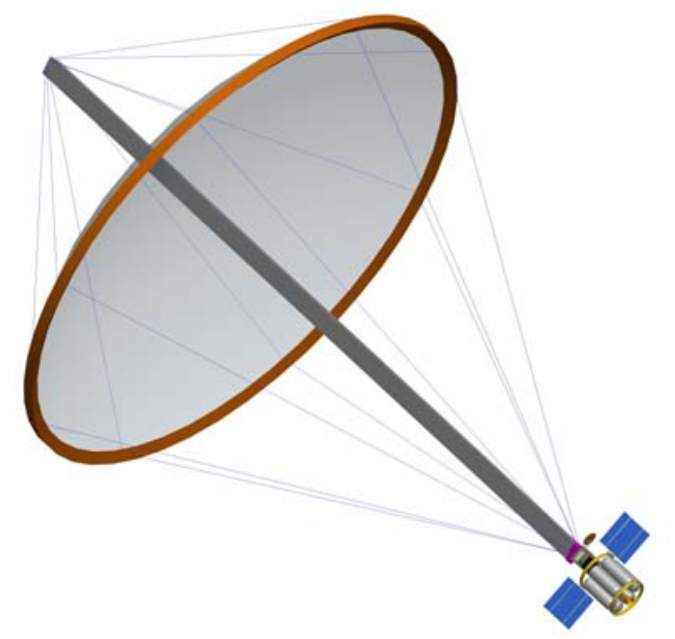

Figure 13: GSS Total System Deployed Configuration

By breaking out of the existing LEO small satellite paradigm, this novel approach offers operational advantages that cannot be achieved by any other means. The GSS supports the ORS goal of meeting the rapidly changing communication needs of the warfighter on the move.

\section{Acknowledgments}

This paper is the result of a team effort by the authors and several SpaceDev team members including Mark Bailey, Marty Holmquist, Bill Jackson, Jesse Koenig, Tony Sandstrom and Harrison Yelton. We would like to thank them all for their support and assistance in completing this study

\section{References}

1. Arthur K Cebrowski and John W. Raymond, "Operationally Responsive Space: A New Defense Business Model," US Army War College Quarterly, pp 67-77, Summer 2005.

2. Jeremy Singer, "Responsive Space" Air Force Magazine Online, Vol 89, No. 3, March 2006

3. Lt. Col. Randall Riddle, Robert Kelsey, Mitch W. Elson, Steven J. Buckley, Scott Schoneman "Operationally Responsive Space Is Here How Using Minotaur Class Vehicles,” RS3-2005-6002, Proceedings of AIAA $3^{\text {rd }}$ Responsive Space Conference, Los Angeles CA, April 2005
4. Orbital, "Pegasus User Guide," http://www.orbital.com/NewsInfo/Publications/peg -user-guide.pdf\#search="Pegasus User Guide", Release 6, June 2007

5. Orbital, "Taurus User Guide," http://www.orbital.com/NewsInfo/Publications/t aurus-user-guide.pdf\#search="taurus", Release 4.0, March 2006

6. Orbital , "Minotaur User Guide," http://www.orbital.com/NewsInfo/Publications/Min otaur_IV_Guide.pdf, Release 1.1, January 2006

7. Space X, "Falcon 1 User Guide," http://www.spacex.com/Falcon\%201\%20Payload\% 20Users\%20Guide.pdf, Rev 6, April 2007

8. Scott Schoneman, "Minotaur IV Calculation out of RTS,” June 2008

9. AmPac, "In-Space Propulsion Brochure," http://www.ampacisp.com/pdf/InspaceBrochure200 5\%20(3).pdf, Niagara Fall NY, May 2008

10. XCOR, “ XR-3E17 56 lbf N2O-Ehtane Stationkeeping - $\quad$ Storable," http://www.xcor.com/products/engines/3E17_N2O _ethane_rocket_engine.html, June 2008.

11. David A. Vallado, "Fundamentals of Astrodynamics and Applications," Second Edition, Microcosm Press, El Segundo, CA, pp 7732001

12. United States Space Command Policy Directive 1039, “Satellite Disposal Procedures," February 2001.

13. Assurance Technology Corporation, " Spaceborne Software Reconfigurable Radio Transceiver Design Study,” October 2006

14. Donald Z. Wadsworth, “ Military Communication Satellite System Multiplies UHF Channel Capacity for Mobile Users,” IEEE Conference Publishing, Piscataway, NJ, 2000

15. G. Campbell, M.C. Bailey and W. K. Belvin, "The Development of the 15-Meter Hoop Column Deployable Antenna System with Final Structural and electromagnetic Performance Results,” NASA Langley Research Center, Hampton, Virginia Acta Astronautica Vol 17, No 1, pp 69-77, February 1987.

16. Charles W. Chandler, "The Case of Deep Space telecommunication Relay Stations,” NASA Glenn Research Ctr, NASA/CR-2004-213053, April 2004. 